\title{
Infusing Service-Learning into Allied Health Profession Curriculum: Perceived Enablers and Barriers
}

Sally Jane Uy

\begin{abstract}
Service learning may offer an innovative perspective in the competing global and national health interests among Philippine universities. The author sought to understand the enablers and barriers of implementing service learning in the context of a premier private Catholic Philippine allied health profession education. Using an in-depth descriptive qualitative design, this study gathered and analyzed by theme transcripts from interviews, field notes and organizational documents. Data were coded and categorized into perceived barriers and enablers, according to The Self-Assessment Rubric for Institutionalization of Service Learning in Higher Education (SRISL) by Furco (2002). A wide range of enablers and barriers to implementing SL in one of the university's health-related program thereby emerged. The results of this study may support further uptake of service-learning as a signature pedagogy in the allied health profession in the Philippines, particularly for its emerging unique professional identity and role in enhancing disability-related health outcomes.
\end{abstract}

Keywords: occupational therapy; Philippine higher education; disability-related health outcomes

\section{Introduction}

A central part of Philippine educational reform is to have universities connect more with communities and provide a reciprocal service orientation in which the universities reach out to their communities with knowledge and services. It mandates Philippine universities to undertake more innovative and transformative approaches to produce future graduates equipped with skills, knowledge, and attitude to respond to local, regional, or national social development needs.

Specifically, the Philippine health system calls for improvement of health services delivery, including its accessibility in the rural and socioeconomically disadvantaged areas. Although advancing health research and medical knowledge has a positive impact on the health of most people, it does not sufficiently address the complex health issues in the Philippines. A first concern is that medical advances cannot replace the humanistic element. Care, empathy and compassion of the healthcare provider, will remain essential components of effective healthcare delivery (McManus, 1991; Burks \& Kobus, 2012). Furthermore, trends in future global workplaces show an increasing need for teamwork and collaborative problem-solving skills, interpersonal communication, and social skills to complement these technical skills (World Economic Forum, 2016).

However, researchers note a decreasing emphasis of these skills in most medical curricula, with the assumption that these skills develop naturally in the 'hidden' curriculum as students navigate their training (Battaglia, 2016; Geraghty et al., 2016). Therefore, in preparing future healthcare 
professionals, it is important for schools to build these skills intentionally into their professional education curriculum (Battaglia, 2016; Burks \& Kobus, 2012; Geraghty et al., 2016). Servicelearning, then, may offer an innovative perspective in these competing global and national health interests among Philippine universities.

Literature supports service learning as a high-impact teaching strategy in higher education (Kuh, 2008) and as a signature pedagogy in the field of occupational therapy education (Schaber, 2014). It offers a broad array of benefits for universities and the communities they serve. However, much of the available literature comes from the United States. Furthermore, the bulk of the literature demonstrates the benefits of service learning among secondary schools and community colleges. Literature on the adoption of service learning among higher education institutions (HEI) remains limited and presents practitioners with more contextual challenges. This study therefore seeks to understand the enablers and barriers to service learning in the context of a premier private Catholic Philippine allied-health professional education.

\section{Literature Review}

Simply defined, service learning (SL) is "an experiential education approach that is premised on reciprocal learning "(Furco, 1996, p. 2). However, SL takes many forms and the literature records a wide range of conceptualizations of service learning. The most widely used definition of SL comes from Bringle and Hatcher (1996, p. 222):

a credit-bearing educational experience in which students participate in an organized service activity that meets identified community needs and reflects on the service activity in such a way as to gain further understanding of course content, a broader appreciation of the discipline, and an enhanced sense of civic responsibility.

Bringl and Hatcher base their formulation on the works of John Dewey and David Kolb's educational and experiential theories. Giles and Eyler (1994) as well as Jacoby, 2014) agree that reflection is a key pedagogical feature of service learning.

Another widely used definition of SL states that:

[s]ervice learning means a method under which students or participants learn and develop through active participation in thoughtfully organized service that is conducted in and meets the needs of a community; is coordinated with an elementary school, secondary school, institution of higher education, or community service program, and with the community; and helps foster civic responsibility; and that is integrated into and enhances the academic curriculum of the students or the educational components of the community service program in which the participants are enrolled; and provides structured time for the students or participants to reflect on the service experience (National and Community Service Act of 1990, p. 13)

Stemming from community development theories, this definition highlights a second key feature of service learning. Reciprocity, as described by Sigmon (1979), helps distinguish service learning from other closely associated terms, such as internship, field education, community 
service and volunteerism. Furco (1996) provided a continuum of this distinguishing feature of reciprocal relationship with his conceptualization of SL. Internship and field education place university students as the locus of control of service provision by deciding who, what and when services will be provided. In contrast, in community service and volunteerism, the recipients control and benefit from these services.

From these descriptive definitions, researchers draw out an understanding of two key features of SL. These are reflection as a pedagogical strategy and reciprocity as a guiding principle for community partnership and learning.

Additional studies find that SL yields significant improvements in student learning and development (Celio, Durlak \& Dymnicki, 2011; Yorio \& Feifei, 2012). Furthermore, recent literature (Battaglia, 2016; Roskell, White \& Bonner, 2012) is widely supports the use of service learning as an experiential pedagogy for developing those humanistic skills said to be in decline in health-related professional curricula. It aids the holistic development of the health professionals, both in discipline-specific skills and generic health professional skills such as interprofessional practice and cultural responsiveness (Crawford et al., 2017).

Aside from the benefits of service learning, current literature continues to explore the practice of service learning among international higher education institutions. There are many more servicelearning programs in the United States than in Australia, Asia, or Africa (Kerins, 2010). Obviously, this poses difficulties in identifying the most critical success factors across different countries. This article seeks to address this gap by exploring factors that support as well as hinder the successful implementation of SL in the Philippines, where this is a relatively new approach.

\section{Support Factors}

Educational and Historical Context as Major Drivers. One of the major drivers of SL was the educational and historical context (Stanton, Giles \& Cruz, 1999). For example, SL flourished in the 1990s as a result of the US government call to augment the role of American higher education in nation-building (National Task Force on Civic Learning and Democratic Engagement, 2012, p. 2). Similarly, the Humboldtian idealism of combining teaching and research together with the European culture of volunteerism has been seen as an opportunity in paving the way of SL in the German universities in the early 2000s (Garrett, Sharpe, Walter \& Zyweitz, 2012). Conversely, Langworthy (2007) argued the contextual difference on Australian historical convict-beginnings and Platonic influence on education made SL not readily embraced widely in Australia.

Change in Mindset for Educational Reform. Launching a SL program requires a change in mindset and it is not simply adding a new program (Stanton, Giles \& Cruz, 1999). SL should not act as a supplement to the formal curriculum, but as a necessary component of student learning, explicitly linked to academic growth. This best distinguishes service learning from volunteer activities (Xing \& Ma, 2010; Zlotkowski, 2011). Sachs and Clark (2017) attributed the success of Macquarie University to its commitment to making community engagement their core business and not as an add-on feature. The synergized tripartite university function legitimized 
service learning as their core business. The creation of a 'hub' integrates it into the university fabric, across disparate functions of teaching, research, and community development. Such structural integration encourages collaboration instead of competition and it institutionalizes service learning (Kezar \& Rhoads, 2001; Roberts et al., 2018). In Asia, education exists solely as an intellectual endeavour. SL called for a shift from this mindset to recognizing "[p]edagogically, service learning comprises of the 'head' plus 'heart' plus 'hands' " (Xing \& Ma, 2010, p. 24).

Design of Service-Learning Program. The role of faculty members in designing appropriate SL activities is crucial to ensure achievement of good learning outcomes. This means ensuring good student-placement fit and well-structured reflection activities. Waterman (2013) found that Student-Placement Fit, defined as meeting the students' motivation (whether intrinsic or extrinsic) during their service-learning experience, significantly affected the success of the program. This also meant that the relevance of the right settings and the related tasks to their course content helped assure that the experience indeed enhanced their learning (Giles \& Eyler, 1994). More importantly, well-structured reflection had the strongest link with the learning outcomes (Celio et al., 2011). In allied-health professional education, Parmenter and Thomas (2015) further found that ongoing reflections, as a key feature of occupation-focused SL, enabled learning about occupational therapy's underpinning paradigm as well as development of professional values of being a therapist.

Enabling Processes. Most literature recommends creation of a separate office to lead service learning (Bringle \& Hatcher, 1996; Furco, 2002). By contrast, Macquarie University use a different organizational structure for its service-learning program. It created a hub as "an (evolving) configuration" (Sachs \& Clark, 2017, p. 277) to encourage institutional collaboration. Furthermore, Sachs and Clark (2017) find that a clear and close alignment between servicelearning objectives and the university's mission and core values is one of the most important successful factors. Macquarie University recognized the unique contribution of SL to higher education through its curriculum. This alignment rationally determined the form SL would take, the breadth of SL across departments and student levels, and the focus of program monitoring and evaluation. This successful implementation of SL at Macquarie University provided case study evidence of how SL has contextually transformed this Australian university (Sachs \& Clark, 2017).

Reciprocity, as the key feature of SL, defines Macquarie University's network and partnerships. Administrators do not measure success by the number of communities enlisted, but rather by the social impact of their programs (Sachs \& Clark, 2017). This reciprocity principle shifted the model of community development from a "needs based" to an "asset based" paradigm. This shift is "in contrast to doing work for communities, in communities or on communities. [The] newer paradigm emphasizes doing work with the community" (Bringle \& Plater, 2017, pp. 301-302).

Resource commitment, particularly financial resources, plays a vital role in the success of any program. Because of limited internal grants and funding, universities need to look for external grants to fund these SL activities. Macquarie University used these grants to offset the incurred costs and subsequently to foster more engagements (Sachs \& Clark, 2017). However, internal 
grants presumably work better towards service-learning implementation without reliance on external funding (Furco, 2002).

Hindering Factors

Alternatively, literature also shows several hindering factors or barriers to implementation of SL that led to the failure or non-institutionalization of SL programs in some universities.

Organizational Culture and Tensions associated with service learning. Kezar and Rhoads (2001) recognize the role of academic leaders in balancing the organizational tensions associated with SL. For instance, Langworthy (2007) argues that the tension between the public good offered by SL interest and the increasing external pressure on workforce outcomes and graduate attributes may have led to the Australian universities not to engage in SL. Moreover, tensions within the organization such as the lack of faculty interest and budgetary support, the lack of time and coordination for SL, and placing SL on a marginal status are the most cited barriers in implementing SL (Bringle \& Hatcher, 1999; Stanton et al., 1999; Waterman, 2013). Reshaping into SL-conducive organizational culture, increasing the incentives for SL engagement, and realigning the recognition and reward system to include SL are some suggestions to resolve these organizational tensions (Kezar \& Rhoads, 2001).

Academic Culture. The academic culture questioning service learning's legitimacy as an academic activity is also a possible hindrance to its implementation. Where does SL fall under the three functions of the university: teaching, research, or community service? Kezar and Rhoads (2001, p. 167) argue that the functional 'organizational boxes' universities need restructuring to encourage interdisciplinary collaboration more conducive to service learning. Garrett et al. (2012) further argue that the challenge of SL in German universities lies on the traditional belief that the concept of educating engaged citizens should be in the public democratic space of society and not necessarily in the more formalistic arena of higher education. Moreover, Langworthy (2007) recommends a change of terminology, to reduce confusion and 'trivialization', and to reflect a more academic or scholarly nature.

Financial Challenges. Funding schemes often make a difference in successful service learning. For instance, federally funded Australian universities rely on the competitive ranking results that emphasize research outputs and employability, not community engagements or impact on social transformation. Langworthy (2007) extrapolates that this was one of the reasons for Australian universities not embracing service learning. Opazo, Aramburuzabala and Cerrillo (2016) conversely attribute much of service learning's success among Spanish Universities to financial support through the European Credit Transfer System (ECTS).

Growing Ethical Concerns. Lastly, Xing and Ma (2010) highlight ethical dimensions of service learning in Asian literature. They explored the extent of the academic community's involvement vis-à-vis the governance of the university and its partner communities. In particular, service learning programs must show they enhance the community's capacity to be self-sufficient over the charitable service provision. Furthermore, possible exploitation issues exist for communities and students, such as the use of free student labor to perform duties otherwise performed by paid workers. 


\section{Methodology}

The initial step in adopting service learning into the context of Philippine higher education is to explore the key support enablers of, and barriers to, service learning in the context of a private Catholic university in the Philippines using the The Self-Assessment Rubric for Institutionalization of service learning in Higher Education (SRISL) by Furco (2002).

SRISL is one of the widely used tool that characterizes the success factors in development of SL in higher education. It utilizes five dimensions, namely, the philosophy and mission of service learning, the faculty support for and involvement in service learning, the student support for and involvement in service learning, the community participation and partnerships and institutional support for service- learning. More than eighty American higher education institutions had used this tool to identify the stage of development of service learning in their institutions and subsequently provide the direction to steer the specific dimensions towards its institutionalization (Furco, 2002).

Implementation science frameworks guided this study in how to adopt successfully new SL programs and practices. Implementation science is utilized to promote the systematic uptake of evidence-based research findings and practices into routine practice to improve the quality and effectiveness of services (Nilsen, 2015). Specifically, determinant frameworks among the implementation sciences recognized that implementation is a multidimensional phenomenon, with multiple interacting influences (Nielsen, 2015). It is generally aimed to understand influences, whether facilitator or barrier, on implementation outcomes. The author chose to use the SRISL, being closely relevant to the service-learning practice and its consistency with the characteristics of these determinant frameworks.

This study used an in-depth descriptive qualitative design. The two sources of data used to inform the analysis were a) semi-structured interviews with thirty-one (31) key stakeholders or intended users about their views about SL and their perceived enablers and/or barriers in its implementation and $b$ ) a document review of relevant organizational reports and plans on service learning in the said university. Transcripts, field notes and organizational documents were analyzed using thematic analysis. Data were coded and categorized into perceived barriers and enablers according to the SRISL framework.

Individual conversations with three key administrative staff, which includes the Vice-Rector for Academic Affairs, SimBahayan Director as the community extension arm of the University, and the Dean of the College of Rehabilitation Sciences, took place on campus. The author also interviewed three department chairpersons, ten faculty members and fifteen students from the College of Rehabilitation Sciences about their views about SL and their perceived enablers or barriers in its implementation using semi-structured questions (Table 1). Reflections and organizational insights on ongoing SL activities grew from these conversations combined with a review of relevant organizational reports and plans. 
Table 1. Interview Questions

\begin{tabular}{|c|c|}
\hline Semi-Structured Questions Used in the Interview & SRISL (Furco, 2002) \\
\hline 1. How do you understand service learning? & Dimension 1: Philosophy and \\
\hline 2. What are possible benefits of service learning? & Mission of service learning \\
\hline $\begin{array}{l}\text { 3. What are examples of service-learning activities } \\
\text { in which you have participated? }\end{array}$ & \\
\hline $\begin{array}{l}\text { 4. What motivates you to participate in service- } \\
\text { learning activities? }\end{array}$ & $\begin{array}{l}\text { Dimension 2: Faculty support for } \\
\text { and involvement in service learning }\end{array}$ \\
\hline $\begin{array}{l}\text { 5. What hampers your participation in service } \\
\text { learning activities? }\end{array}$ & $\begin{array}{l}\text { Dimension 3: Student support for } \\
\text { and involvement in service learning }\end{array}$ \\
\hline $\begin{array}{l}\text { 6. How does the community view the participation } \\
\text { of students in service learning? }\end{array}$ & $\begin{array}{l}\text { Dimension 4: Community } \\
\text { participation and partnerships }\end{array}$ \\
\hline $\begin{array}{l}\text { 7. How does the university view the participation } \\
\text { of students in community activities? }\end{array}$ & \\
\hline $\begin{array}{l}\text { 8. How has service learning evolved in the College } \\
\text { and/or University? What factors led to this } \\
\text { current state of service learning? }\end{array}$ & $\begin{array}{l}\text { Dimension 5: Institutional support } \\
\text { for service- learning }\end{array}$ \\
\hline $\begin{array}{l}\text { 9. What problems or challenges did you encounter } \\
\text { in engaging with communities? How did you } \\
\text { manage or resolve them? }\end{array}$ & \\
\hline
\end{tabular}

\section{Results and Discussion}

Background on the University of Santo Tomas

The University of Santo Tomas (UST) is one of the top universities in the Philippines with twenty-three (23) colleges and fifty-six (56) undergraduate academic programs. It is a 400-yearold private Catholic university with a 20,000-student population. As the Royal and Pontifical University of the Philippines, the University is renowned as a strong traditional educational institution. This paper focused on one particular unit called as the College of Rehabilitation Sciences (CRS). It is one of several health-related colleges. It offers four programs: (a) Physical Therapy (PT); (b) Occupational Therapy (OT); (c) Sports Science (SPS); and (d) Speech and Language Pathology (SLP). The Dean of the college is responsible for its overall operation. Department chairpersons manage their respective programs.

Our subjects discussed a wide range of enablers and barriers to implementing SL in CRS. The significant perceived enablers were the implicit alignment of institutional mission with service learning, the early service-learning groundwork in each department, faculty members' enthusiasm, the preferred partner communities and the symbolic administrative support for service-learning initiatives. The perceived barriers were: (a) fragmented views among students, faculty and administration; (b) restricted faculty and student engagement; (c) minimal incentives for faculty and students to participate in service-learning; (d) the limited 'reciprocity' concept among the partner communities; and (d) the lack of actual administrative commitment and support. The result of this self-assessment also showed the early stages of development of service learning at UST. 


\section{Perceived Enablers}

Implicit Alignment of Institutional Mission with SL. SL activities appeared to be peripheral to UST's institutional goals and strategies. As a Catholic university guided primarily by the teachings of St. Thomas of Aquinas, UST's mission has three core values: competence, compassion and commitment. While the components of compassion and commitment are clearly relevant elements of SL, the curriculum does not explicitly link these to achieve one of the key graduate attribute of servant leadership. In the same light, the Thomasian educational philosophy of contemplative study in service of truth (Lorezca-Tangco, 2014), though closely attuned with SL, was not clearly evident in its curriculum. Competence in professional therapy practice appears to be the main focus of the curriculum design. Thus, it lacked a clear link to the socialtransformation mission stated in its strategic plans. Specifically, students and faculty members see little evidence, so far, for CRS's strong social-transformation agenda for the vulnerable and marginalized population of people with disabilities.

Beginning Service-Learning Groundwork. The Dean recognized that the OT department took the lead on SL development when it introduced a community-based rehabilitation (CBR) course into its curriculum in 2010, and expanded to introduce social justice issues using a rehabilitationscience lens. It was admittedly difficult at the beginning for the OT department to gain acceptance and legitimacy of this pedagogy. As an evolving course, CBR offered a relatively new perspective on disability-related health issues by putting the community as the focal point for disability prevention and health promotion activities for allied health professionals.

Nevertheless, CBR shifted the paradigm from a medical to biopsychosocial model of disability, with the twofold benefit of attaining student outcomes and meeting community health needs (Sagun-Ongtangco \& Abenir, 2016). The CBR course not only expanded the disability-related practice of occupational therapy, but also helped develop a unique professional identity in the Philippine setting.

Optimism of Faculty Members. Despite claiming it was their first time to hear about SL or having limited understanding of SL, faculty members have discussed various elements of SL in their current practice such as:

I think our community-based rehabilitation (CBR) course is an example of service learning because it is geared towards community development through disability prevention. (Faculty member 1)

Our internship program has a community setting as one of the students' placement. (Faculty member 2)

We encourage our students to participate in Lib-Rehab, an annual program of providing free therapy services in the community. (Faculty member 7)

The current group of interns are conducting research on tele-rehab in the community in exchange for free rehabilitation services to its community members. (Faculty member 8) 
These responses showed that SL is closely associated with working in a community (locational purpose) and working on a community (therapy service provision). Moreover, it also appeared that SL is closely intertwined with the nature of the therapy profession, which is inherently part of the allied health professional identity (Parmenter \& Thomas, 2015). As such, community involvement becomes integral part of the allied health profession curriculum for developing both professional therapy and humanistic skills. Although the lack of reflective pedagogical strategy and attendance grades diluting the basic essence of SL, there were also some faculty members who saw the potential of SL to:

Not only develop these humanistic skills but also to promote social justice as perceived from the rehabilitation science lens. Recognition of health disparities and inequitable access to healthcare services are among the many social problems that need to be incorporated into the service-learning program. (Faculty member 5).

This recognition may lead to the potential expansion of SL into the social change agenda as described by Butin (2010), including disability-related health reforms such as disability-inclusive communities.

Preferred Partner Communities. SimBahayan, as the community development arm of the University, acted as the liaison between the community and the Colleges, matching the academic needs with the community needs. SimBahayan Director proudly shared that the number of partner communities had increased to one hundred twenty (120) over a few years. The program uses a needs-based framework, by which the University identified and established the needs of partner communities prior to forming a partnership (Director of SimBahayan).

For CRS, it was relatively easy to establish disability-focused community partnerships in rural and socio-economically disadvantaged areas, with limited access to therapy and health services. It included public schools, rural health units, villages and non-profit organizations with disability-related concerns, among many others. Most of these activities were discipline-specific, and were thought of as extra-/co-curricular in nature, such as free health screening, wellness programs, English language classes, book reading for education and humanities programs, and tree-planting or community clean-ups for the social sciences programs.

Symbolic Administrative Support. The organizational structure of the University clearly reflects its tripartite functions of instruction, research and extension services. Each function is clearly the province of a Vice-Rector controlling an operational budget. For the instruction function, there is the Office of Vice-Rector for Academic Affairs. For the research function, there is the Office of Vice-Rector for Research and Innovation. For extension services or community development, there is the SimBahayan office, under the Office of Vice-Rector for Religious Affairs. Being a Catholic University, SimBahayan represented the union of Church (SIMbahan), Family (BAHAY) and Nation (bayAN). SimBahayan was the innovative result of the quadricentennial celebration of the University in 2010. 


\section{Perceived Barriers}

Fragmented Views. The most common SL understanding reported by both faculty members and students is community service, either curricular, co-curricular or extra-curricular. Some students associated SL with internship. They shared stories about their experiences of practising the skills learned in the classroom with real patients (in contrast with simulated patients). Some faculty members and students related SL to occasions when they volunteered their services in the community (as compared to the clinic or hospital). Few faculty members described SL as an exchange between learning skills for disability-inclusive community development by students and the empowerment of partner communities on disability-related health issues. Two faculty members mentioned that both community and the academe shared the mutual benefit of SL with an end goal of improving the disability-related health outcomes in their communities.

The department chairpersons raised a different perspective. They focused on the pedagogical component of SL and its impact on the values formation and humanistic skills such as cultural competency and interprofessional collaboration skills.

The administrative officials had more fragmented views on SL. On the one hand, the CRS Dean viewed it as a way to merge research and community service. On the other hand, the SimBahayan Director viewed it as mobilizing the students to participate in socially-relevant activities. He further elaborated that SimBahayan will get a boost in support and funding if it portrayed the university as an international SL hub, reportedly important for the university's ranking and program accreditation purposes. Furthermore, the Vice-Rector for Academic Affairs viewed it as the pedagogical tool that will shape future Thomasian graduates as global citizens.

Reflection as a learning strategy received little mention in these conversations. Participants may have assumed that learning had occurred because of their community experience. The role of faculty in facilitating learning through reflective strategies was not evident. Reflection, as a key pedagogical feature of SL, was not explicitly elucidated in these conversations.

This fragmented vision of SL on the part of various stakeholders indicated a strong need to clarify and harmonize SL understanding to appreciate its intended benefits, particularly in the allied health profession curriculum.

Restricted Engagement of Faculty and Students. Limited understanding and time constraints resulted in minimal faculty involvement.

I would like to be part of community activities, but I have no more time for this. (Faculty member 8)

Inasmuch I would like to make frequent community visits with my class, we don't have the extra time to do so. (Faculty member 2) 
Although opportunities for SL were available to students, their academic workload took a higher priority:

We would like to do it, but our academic studies come first. If only we have spare time, we would participate in community activities. (Student 3)

It takes so much time to get into the communities . . . and the traffic jam makes it horrible. The travel time actually makes it difficult, not the actual activity. (Student 4)

Similarly, students perceived the National Service Training Program (NSTP), a nationally mandated course for all first-year students to engage with the community, as a 'hassle' or irrelevant to their learning to become allied health professionals, as it lacked in the utilization of health-related skills in their community activities. Compliance to the traditional allied medical profession curriculum design seemed to be more appealing to students than the altruistic values of SL.

Minimal Incentives. Faculty members considered community service as a non-rewarding work. They under-recognized it as an innovative pedagogy. A number of faculty members shared that engaging in community service contributed little to their faculty promotion. They were further pressed to balance the three functions of teaching, research, and community service, with the latter most likely neglected. Researchers and advocates have consistently raised this as a key barrier to SL implementation (Roberts et al., 2018). With time-consuming logistical preparations, compounded by compliance with tedious government regulatory requirements for off-campus activities, some faculty members felt unmotivated and considered it not a worthwhile activity.

Similarly, there were few incentives for students to participate in SL activities. Accustomed as they were to mandatory attendance requirements in their courses, students claimed they expected a reward for their participation, either with an attendance grade or through bonus points for meritorious effort. For the faculty members, they gave these bonus points because "without these incentives, students will most likely not participate in such extra work" (Faculty member 5). This counteracted the key feature of SL, in which students receive grades based on their learning outcomes, not solely on their participation (Zlotkowski, 2011).

Limited Reciprocity. While the number of partner communities has increased over time, SL's impact on the community and/or student learning remains unexplored. The quality of these programs and partnerships, and their impact on social transformation will need more attention. SimBahayan usually arranges the community activities and specifies the number of participants, resources, dates, and times according to the availability of the students and faculty. The Director found this convenient, as partner communities readily altered their stated needs to accommodate SimBahayan's constraints, in return for free services. The concept of 'reciprocity' (Sigmon, 1979 , p. 10), understood as placing resources in the hands of those being served, was not evident in this example.

Limited Actual Buy-in. Despite the potential of SL to influence graduate outcomes, the departmentalized organizational structure may often lead to silo thinking in teaching, research, and service functions. Therefore, this may limit the collaborative culture needed to cultivate SL. 
Moreover, limited student and faculty recognition, grants and awards were available for successful achievement. Conversely, instances of non-compliance reportedly received negative reinforcements, such as budget reduction and increasing procedural bureaucracy. This nonpositive organizational culture may have hindered the creative and innovative thinking necessary for SL to take a richer form in this university.

The faculty and students alike confronted multiple layers of bureaucracy for community engagement. The SimBahayan Director may symbolically oversee the university's function in community development. However, both the student affairs office and the academic affairs office have the most to say in approving extra-curricular activities. The community-development coordinators monitor the community activities within their colleges, while the department chairpersons monitor the integration of SL as a pedagogy in their respective departments. Highlighting this lack of a coordinating entity, the SimBahayan Director lamented that:

The recent CHED policies have reduced the number of community activities of the students by $50 \%$. There has been so much time, effort and money just to get those CHED permits and it had to be cancelled at the last minute because the permits were not processed in time. (SimBahayan Director)

The Director lamented further that the modest budget allocated to SimBahayan did not support all the community-related activities. Most often, students had to do their own fund-raising to implement their community-related activities. Furthermore, faculty and students often competed for the same sponsors. For instance, the mayor's office of the partner community might be asked to fund the transportation and food expenses for different activities.

These conversations indicated that SL in UST may potentially be the vital link in fulfilling its Thomasian educational mission, but it may need to: (a) organize more effectively; and (b) implement SL so as to effect the authentic social transformation it hopes to achieve. The fragmented understanding of SL, seen as mostly mandatory, extra-curricular activities within the community (rather than with the community), is typically characteristic of early stages of SL program development. Reciprocity, as a key element of SL, can be further enhanced to overtly align the Thomasian educational mission and disability-related health SL initiatives. Furthermore, CRS faculty should reconsider employing pedagogical reflection strategies on SL activities to bring the humanistic skills of compassionate care into the allied health curriculum.

The tripartite structure and academic culture of the university shaped the way SimBahayan functioned as a separate unit from teaching and research. Such organizational tensions may contribute to defeating the altruistic intentions of service learning. Beyond serving as an essential coordinating entity, SimBahayan should provide a broader range of pedagogical and research support and ethical practice to support institutionalization of SL in the University. By recognizing the early stage of development of SL in UST, it has already shown potential growth and development opportunities to fulfill its 400 -year-old Thomasian mission in modern times. The SRISL tool had helped identify the specific enabling dimensions, which can aid in overcoming the perceived barriers. Ultimately, these strengths shall help advance the institutionalization of SL program at the University. 


\section{Conclusion}

Responding to the call for relevant allied-health professional education, we need to ensure that learning experiences in the actual communities contribute to the redesign of health service delivery, as well as to allied health professional development. This study highlighted the multidimensional perspectives from the academic community of faculty members, students and the partner communities regarding many key concepts which may affect the SL implementation. While the benefits of SL are clear to the academic landscape, it was apparently not adequate to drive its successful implementation to attain its graduate outcomes as well as the resultant disability-related health outcomes for the communities we serve. The results of this study may inform development of continuing education, training and support for service-learning initiatives for further uptake of service learning as its signature pedagogy in the allied health profession. SL can potentially support allied health profession curriculum for its emerging professional identity and role in enhancing disability-related health outcomes. Likewise, the fragmented views, time constraints and limited institutional buy-in of SL are the key barriers in need of attention as practitioners advance signature SL in allied-health professional education. This may potentially make service learning a core component of the allied health education curriculum and further scale up service learning across the various programs in the university. 


\section{References}

Battaglia, J. (2016). Toward a caring curriculum: Can occupational therapy be taught in a caring context? International Journal of Teaching and Learning in Higher Education, 28(2), 265-270. Retrieved from https://files.eric.ed.gov/fulltext/EJ1111119.pdf

Bringle, R. G., \& Hatcher, J. A. (1996). Implementing service learning in higher education. The Journal of Higher Education, 67(2), 221-239. doi:10.1080/00221546.1996.11780257

Bringle, R.G. \& Plater, W.M. (2017). Reflections on Macquarie Experience. In Sachs, J. \& Clark, L. (Eds.) Learning through community engagement: Vision and practice in higher education (pp. 301-317). doi: 10.1007/978-981-10-0999-0

Burks, D. J., \& Kobus, A. M. (2012). The legacy of altruism in health care: the promotion of empathy, prosociality and humanism. Medical Education, 46(3), 317-325. doi:10.1111/j.13652923.2011.04159.x

Butin, D. W. (2010). Service learning in theory and practice. The future of community engagement in higher education. NY: Palgrave Macmillan.

Celio, C. I., Durlak, J., \& Dymnicki, A. (2011). A Meta-analysis of the impact of service learning on Students. Journal of Experiential Education, 34(2), 164-181. doi:

10.5193/JEE34.2.164

Crawford, E., Caine, A. M., Hunter, L., Hill, A. E., Mandrusiak, A., Anemaat, L., \& Quinlan, T. (2017). Service learning in developing countries: Student outcomes including personal successes, seeing the world in new ways, and developing as health professionals. Journal of Interprofessional Education \& Practice, 9, 74-81. doi:/10.1016/j.xjep.2017.08.006

Furco, A. (1996). Service learning: A balanced approach to experiential education. Expanding Boundaries: Service and Learning. Cinncinati, OH: Cooperative Education Association, 2-6. Retrieved from

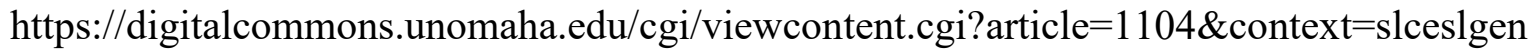

Furco, A. (2002). Assessment rubric for the institutionalization of service learning in higher education. Boston, MA: Campus Compact.

Garrett, C., Sharpe, C., Walter, M., \& Zyweitz, M. (2012 Fall). Introducing service learning to Europe and Germany: The case of American studies at the University of Leipzig. Interdisciplinary Humanities, 29(3), 147-158.

Geraghty, S., Oliver, K., \& Lauva, M. (2016). Reconstructing compassion: should it be taught as part of the curriculum? British Journal of Nursing, 25(15), 836-839.

doi:/10.12968/bjon.2016.25.15.836 
Giles, D.E. \& Eyler, J. (1994). The theoretical roots of service learning in John Dewey: Toward a theory of service learning. Michigan Journal of Community service learning, 1(1), 77-85.

Jacoby, B. (2014). Service-learning essentials. Questions, answers, and lesson learned. New York: John Wiley \& Sons.

Kerins, A. T. (2010). An Adventure in service learning: Developing Knowledge, Values and Responsibility. Farnham, Surrey: Gower Publishing, Ltd.

Kezar, A., \& Rhoads, R. A. (2001). The dynamic tensions of service learning in higher education: A philosophical perspective. The Journal of Higher Education, 72(2), 148-171. doi:/10.1080/00221546.2001.11778876

Kuh, G.D. (2008). Excerpt from high-impact educational practices: What they are, who has access to them, and why they matter. Association of American Colleges and Universities.

Langworthy, A. (2007). Education for the public good: is service learning possible in the Australian context? The Australasian Journal of University Community Engagement, 2(1), 70 80 .

Lorezca-Tangco, B. (2014). Dominican education at the University of Santo Tomas, Manila: Towards 400 years of unending grace. In Kelly G. \& Saunders K. (Eds.), The Dominican Approaches in Education (pp. 337-346). ATF (Australia). Retrieved from http://www.jstor.org.ezp.lib.unimelb.edu.au/stable/j.ctt163t8vb.39

McManus, I. C. (1991). How will medical education change? Lancet, 337(8756), 15-19. National and Community Service Act of 1990. (United States). S. 40. Retrieved from https://www.nationalservice.gov/sites/default/files/page/Service_Act_09_11_13.pdf

National Task Force on Civic Learning and Democratic Engagement. (2012). A crucible moment: College learning and democracy's future. Washington, DC: Association of American Colleges and Universities.

Nilsen, P. (2015). Making sense of implementation theories, models and frameworks. Implementation Science, 10 (1), 53. doi:/10.1186/s13012-015-0242-0

Opazo, H., Aramburuzabala, P., \& Cerrillo, R. (2016). A review of the situation of service learning in higher education in Spain. Asia-Pacific Journal of Cooperative Education, 17(1), 7591.

Oracion, C. C. (2014). Teacher leadership in public schools in the Philippines (Unpublished doctoral dissertation). University of London Institute of Education, London.

Parmenter, V., \& Thomas, H. (2015). WOW! Occupational therapy education and experiential service learning through community volunteering. British Journal of Occupational

Therapy, 78(4), 241-252. doi:/10.1177/0308022614563945 
Roberts, R., Wilson, A., Coveney, J., Lind, C., Tieman, J., George, S., \& Tonkin, E. (2018). Role of community and professional engagement in allied health higher education: The academic perspective. Journal of Allied Health, 47(3), 87E-90E.

Roskell, C., White, D., \& Bonner, C. (2012). Developing patient-centred care in health professionals: reflections on introducing service learning into the curriculum. International Journal of Therapy and Rehabilitation, 19(8), 448-457. doi:/10.12968/ijtr.2012.19.8.448

Sachs, J., \& Clark, L. (Eds.). (2017). Learning through community engagement: Vision and practice in higher education. Singapore: Springer. doi: 10.1007/978-981-10-0999-0

Sagun-Ongtangco, K. \& Abenir, M.A. (2016). A case study applying a service-learning approach: Occupational therapy in community health. In The Second International Conference on service learning, 1, 167-171.

Schaber, P. (2014). Keynote address: Searching for and identifying signature pedagogies in occupational therapy education. American Journal of Occupational Therapy, 68, 40-44. doi: 10.5014/ajot.2014.685S08

Sigmon, R. (1979). Service learning: Three principles. Synergist, 8(1), 9-11.

Stanton, T., Giles, D., \& Cruz, N. (1999). Service learning: A movement's pioneers reflect on its origins, practice and future. San Francisco, CA: Jossey-Bass Publishers.

Waterman, A. S. (Ed.). (2013). Service learning: Applications from the research. New York, New York; East Sussex, England: Psychology Press.

World Economic Forum (2016). The future of jobs: Employment, skills and workforce strategy for the fourth industrial revolution. Retrieved from http://www3.weforum.org/docs/WEF_Future_of_Jobs.pdf

Xing, J., \& Ma, C. H. K. (Eds.). (2010). Service learning in Asia: Curricular models and practices. China: Hong Kong University Press. Retrieved from http://www.jstor.org.ezp.lib.unimelb.edu.au/stable/j.ctt1xwf3j

Yorio, P. L., \& Feifei, Y. (2012). A meta-analysis on the effects of service learning on the social, personal, and cognitive outcomes of learning. Academy of Management Learning \& Education, 11(1), 9-27. doi: 10.5465/amle.2010.0072

Zlotkowski, E. (2011). Pedagogy and Engagement. In Zlotkowski, E., \& Saltmarsh, J. (Eds.) Higher education and democracy: Essays on service learning and civic engagement. (pp. 95119). Temple University Press. Retrieved from http://www.jstor.org.ezp.lib.unimelb.edu.au/stable/j.ctt14bt5qz.13 


\section{Author Information}

Sally Jane Uy, MEd(Melb), MBAH, OTRP, OTR

Associate Professor

Department of Occupational Therapy

College of Rehabilitation Sciences

University of Santo Tomas

España Boulevard, Sampaloc

Manila, Philippines

Email: shuy@ust.edu.ph / sjuy22@gmail.com

Contact Number: +639176290207

Sally Jane Uy is currently an associate professor at the College of Rehabilitation Sciences and Graduate School of the University of Santo Tomas. She has more than twenty years of experience as an occupational therapist in the clinical setting and the academe. She recently obtained her Masters in Educational Management from the University of Melbourne under the Australia Awards program. 